Original Article

\title{
DEVELOPMENT AND CHARACTERIZATION OF DICLOFENAC SODIUM LOADED EUDRAGIT RS100 POLYMERIC MICROSPONGE INCORPORATED INTO IN SITU GEL FOR OPHTHALMIC DRUG DELIVERY SYSTEM
}

\author{
RAJASHRI B. AMBIKAR ${ }^{*}$, ASHOK V. BHOSALE ${ }^{2}$
}

1PDEA's Seth Govind Raghunath Sable College of Pharmacy, Saswad, Purandar, Pune, Maharashtra, India, 2PDEA's Shankarrao Ursal College of Pharmaceutical Sciences and Research Centre, Kharadi, Pune, Maharashtra, India

Email: rajashriwin@gmail.com

Received: 14 Jun 2021, Revised and Accepted: 28 Jul 2021

\section{ABSTRACT}

Objective: Purpose of the study to design and formulate Diclofenac sodium (DIC) microsponges.

Methods: With varied polymer: drug ratio DIC loaded microsponges were prepared with Eudragit RS100 polymer by quasi solvent diffusion method. Microsponges evaluated for particle size, entrapment efficiency, drug content, in vitro drug release, Fourier Transform Infrared Spectroscopy (FTIR), Differential scanning calorimetry (DSC) and Scanning electron microscopy (SEM). DIC loaded microsponges incorporated into ocular in situ gel to attained controlled release by microsponge and improved residence time by gelling system. Ocular in situ gel evaluated for $\mathrm{pH}$, drug content determination, gelling capacity, in vitro drug release and sterility study.

Results: DSER4 microsponge formulation having polymer to drug ratio 1:7 showed satisfactory production yield (68.13\%), entrapment efficiency (62.86\%), drug content (80.73\%), requisite particle size (less than $10 \mu \mathrm{m})(7.52 \mu \mathrm{m})$ and in vitro release 87.94\% after $6 \mathrm{~h}$. Selected DSER4 formulation was incorporate into in situ gel. Carbopol 940 forms stiff gel at higher $\mathrm{pH}$ so used as a gelling agent, whereas Hydroxypropyl Methylcellulose E4M was used as a viscosity-enhancing agent for the formulation of in situ gel in varied compositions. In situ gel formulation IG4 showed sustained release of $76.92 \%$ till the end of $8 \mathrm{~h}$ and satisfactory gelling capacity so IG4 further evaluated for sterility test. Rheological studies reveal the sol-gel transition of in situ gel occur at the physiological condition to form stiff gel.

Conclusion: Prepared in situ gel formulations showed sustained drug release for a period of $8 \mathrm{~h}$, which is satisfactory for management of ocular pain.

Keywords: Microsponge, Ocular in situ gel, Controlled release, Ophthalmic drug delivery, Kinetic release

(C) 2021 The Authors. Published by Innovare Academic Sciences Pvt Ltd. This is an open access article under the CC BY license (https://creativecommons.org/licenses/by/4.0/)

DOI: https://dx.doi.org/10.22159/ijpps.2021v13i9.42405. Journal homepage: https://innovareacademics.in/journals/index.php/ijpps.

\section{INTRODUCTION}

Microsponges are polymeric particulate delivery systems having 5 to $300 \mu \mathrm{m}$ diameter with a porous spherical structure formed with polymer enclosing active drug ingredients and thereby control drugs release [1]. Microsponges are drug-contained polymeric sponge-like structures with large porous surface and non-collapsible structure made through numerous of interconnecting voids. Microsponges display good stability for extreme acidic ( $\mathrm{pH} 1)$ to extreme basic $\mathrm{pH}$ 11) conditions also stable at high temperatures (up to $130^{\circ} \mathrm{C}$ ). This entrapment technologies offer high drug payload than others [2].

Several different research works of microsponges explored on various areas like colonic delivery [3-5], topical delivery [6, 7], gastroretentive delivery [8] and percutaneous delivery [9] for controlled and sustained drug release. Fewer attempts have been made for ophthalmic drug delivery [10-12] of microsponges.

Ophthalmic drug delivery systems have the main problem of fast and substantial precorneal loss, caused by high turnover of tear fluid and further draining of tear fluid form eye [13]. Particulate system suffers from this nasolacrimal drainage. This possibility of short residence time is eliminated by the incorporation of particulate system in situ gel and increases its retention in eye. A lot of attempts have been made on the incorporation of particulate system in ocular in situ gel [14, 15]. But lesser studies are carried out on microsponge-loaded ocular in situ gel.

In situ gels, upon installation in ocular cul-de-sac, go through a solgel phase transition to form a stiff gel. Phase transition occurs from droppable low viscous solution to stiff gel by the influence of physicochemical changes i.e. $\mathrm{pH}$, temperature and ions composition, caused by tear fluid. This system allows administration of accurate doses in the form of drop and augmented residence time which in turn improves bioavailability at ocular area [16].

Carbopol is a polyacrylic acid (PAA) polymer, which go through a sol to gel conversion in an aqueous solution with a change in $\mathrm{pH}$ above its $\mathrm{pKa}$ of about 5.5. However, the high amount of carbopol required to get stiff gel results in highly acidic solutions. Such acidic polymeric solution is unable to neutralize with the buffering capacity of the tear fluid. So to good gelling capacity could be achieved with no further increment in the amount of carbopol in polymer solution; by adding HPMC polymer as viscosity enhancing polymer [17]. HPMC E4M was selected for in situ gel formulation as its frequent use in ophthalmic drug delivery, reliability, superior transparency and less incompatibility [18].

Diclofenac sodium is effectively used for pain management in cases of corneal epithelial defects followed by surgery or accidental trauma, and prevention of intraoperative miosis during cataract surgery, treatment of postoperative ocular inflammations, chronic non-infectious inflammations and for symptomatic relief of seasonal allergic conjunctivitis [19].

The purpose of this study is to attain controlled release through microsponge and improve its residence time by incorporating microsponges in in situ gel. Eudragit RS100 is used as a polymer for the preparation of microsponges. Further microsponges were added to HPMC E4M and carbopol in situ gel.

\section{MATERIALS AND METHODS}

\section{Materials}

Diclofenac Sodium (DIC) was gifted by Nulife Pharmaceuticals, Pune, India. Eudragit RS 100 (ERS) and Hydroxypropyl Methylcellulose E4M (HPMC E4M) was gifted from Evonik India Pvt. Ltd., Mumbai and 
Colorcon Asia Pvt. Lmt., Goa, India respectively. Carbopol 940, Dichloromethane (DMC), Triethylcitrate, Polyvinylalcohol 30,00070,000 (PVA) were procured from Research lab fine chem. Industries, Mumbai. All other chemicals used for analysis were analytical grade.

\section{Preparation of DIC loaded microsponges}

For the preparation of DIC-loaded microsponges with ERS polymer; the quasi-emulsion solvent diffusion method was considered. To prepare internal phase ERS polymer and triethylcitrate $(1 \% \mathrm{w} / \mathrm{v})$ dissolved in dichloromethane. To the prepared solution of polymer, DIC was added and homogenously dispersed by ultrasonication to achieve particle size reduction. Polymer: drug ratio was varied as $1: 1$ to $1: 13$. The internal phase was added dropwise to $100 \mathrm{ml}$ of $1 \% \mathrm{w} / \mathrm{v}$ PVA solution. This emulsion was stirred for $4 \mathrm{hr}$ using magnetic stirrer at $1000 \mathrm{rpm}$. The DIC loaded microsponges were filtered, washed with double distilled water and then dried for $48 \mathrm{~h}$ at room temperature. DIC-loaded microsponges stored for further characterization $[5,20]$.

\section{Characterization of DIC loaded microsponge}

\section{Determination of Percentage Yield}

The percentage yield of obtained microsponges was determined by calculating the percentage of the weight of the DIC loaded microsponges and the collective weight of DIC and ERS polymer.

$$
\text { Production yield }=\frac{\mathrm{WPr}}{\mathrm{WTh}} \times 100 \ldots(\text { Equation } 1)
$$

Where,

\section{$\mathrm{W}_{\mathrm{Pr}}=$ Practical mass of DIC loaded microsponges}

$\mathrm{W}_{\mathrm{Th}}=$ Theoretical mass (Total weight of DIC and ERS polymer added to formulation)

\section{Drug content}

DIC-loaded microsponge formulation equivalent to $10 \mathrm{mg}$ of DIC of each batch was finely crushed in a glass mortar. Further to this add $60 \mathrm{ml}$ of phosphate buffer ( $\mathrm{pH} 7.4$ ) and the solution was shaken for 4 h. to dissolve DIC and, filtered. Filtered solution was diluted to 100 ml with 7.4 phosphate buffer. The resultant solution was analyzed on UV spectrophotometer (Jasco V-530) at $275.5 \mathrm{~nm}$. The DIC content of the microsponges $\left(\mathrm{D}_{\mathrm{At}}\right)$ was calculated.

\section{Entrapment Efficiency (\%)}

Entrapment Efficiency (\%) of DIC contained microsponge was calculated with an equation,

$$
\text { Entrapment Efficiency }(\%)=\frac{\text { DAt }}{\text { DTH }} \times 100 \ldots(\text { Equation } 2)
$$

Where,

$$
\begin{aligned}
& \mathrm{D}_{\mathrm{At}}=\text { Actual drug content in Dried microsponges } \\
& \mathrm{D}_{\mathrm{Th}}=\text { Practical drug content (Weight of DIC added in microsponges) }
\end{aligned}
$$

\section{Particle size}

Optical microscopy was used to measure particle size of microsponge by using digital microscope (Motic CV5-2), calibrated with ocular micrometer (AmScope MR400 Microscope calibration slide). Selected microsponge formulation was dispersed in water and few drops were placed on a glass slide. The drop of dispersion was observed under a digital microscope. The mean of particle size for 300 particles was calculated [21].

\section{In vitro drug release from DIC loaded microsponges}

Franz diffusion cell was used to carry out in vitro drug release of DIC-loaded microsponges. Freshly prepared STF of pH 7.4 was filled in the receptor compartment of the Franz diffusion cell and with a small magnetic bar STF was constantly stirred at $100 \mathrm{rpm}$. A dialysis membrane (12 000-14 000 Dalton MW, Hi-media, India) soaked for $12 \mathrm{~h}$ in the STF and stretched in between donor and receptor chambers. DIC loaded microsponge dispersed in distilled water and placed in donor compartment; and covered with a coverslip. Samples each of $1 \mathrm{ml}$, were withdrawn for at predetermined time intervals from the receptor chambers and replaced with fresh STF and sink conditions. In vitro drug release was performed thrice for each formulation; further samples were analyzed by measuring the absorbance at $275.5 \mathrm{~nm}$ using UV spectrophotometer [22].

\section{In vitro drug release kinetic study of DIC loaded microsponges}

Drug Kinetic model studies of in vitro release data of microsponge formulations were performed to conclude the DIC release mechanism. In vitro release data was fitted to the following models and regression coefficient values $\left(\mathrm{r}^{2}\right)$ were calculated.

- Zero-order kinetic model $\left(\mathrm{d}_{0}-\mathrm{d}=\mathrm{Kt}\right)$

- $\quad$ First order kinetic model (log $\left.d=\log d_{0}-K t / 2.303\right)$

- Hixson-crowell kinetic model $\left(\mathrm{d}_{0}{ }^{1 / 3}-\mathrm{d}^{1 / 3}=\mathrm{Kt}\right)$

- Higuchi kinetic model $\left(\mathrm{d}_{0}-\mathrm{d}=\mathrm{Kt}^{1 / 2}\right)$

Where $d$ is the quantity of the DIC remaining in the microsponge at time $t$ and $d_{0}$ is the initial amount of the DIC in the microsponge. Diffusion mechanism was explained by the diffusion exponent (n) value of Korsmeyer-Peppas equation $\left(\mathrm{d}_{0}-\mathrm{d} / \mathrm{d}_{0}=K \mathrm{t}^{\mathrm{n}}\right)$. The diffusion exponent value $\mathrm{n}<0.45$ signifies the release follows fickian mechanism. If exponent value indicates $0.5<\mathrm{n}<0.8$ signifies the release follows the non-fickian mechanism [23].

\section{Fourier transform infrared spectroscopy (FTIR)}

FTIR spectra of DIC, physical mixture of DIC and ERS polymer and; selected microsponge formulations were recorded in ATR mode with a Perkin Elmer (Model: SPECTRUM BX).

\section{Differential scanning calorimetry (DSC)}

Thermal analysis of DIC and the selected microsponge were scanned at a rate of $20^{\circ} \mathrm{C} / \mathrm{min}$ on a Differential scanning calorimetry (Mettler Toledo, Model: StareSW920, Mumbai) between $40{ }^{\circ} \mathrm{C}$ and $320{ }^{\circ} \mathrm{C}$ under dynamic nitrogen atmosphere DSC studies were carried out intend to find out any incompatibility.

\section{Scanning electron microscopy (SEM)}

A Field Emission Scanning Electron Microscope (FEI Nova NanoSEM 450 ) operated at $3.00 \mathrm{kV}$ and magnification of $\times 500$ and $\times 5000$; was used to study the morphology of microsponges. Selected microsponge need to coat with gold-palladium alloy for $45 \mathrm{~s}$ under an argon atmosphere before observation.

\section{Formulation of DIC loaded microsponges containing ocular in situ gel}

Ocular in situ gel formulations containing varied concentrations of Carbopol 940 and HPMC E4M were prepared as per the composition summarized in table 1. Accurately weighed HPMC E4M was dispersed in $50 \mathrm{ml}$ of distilled water and carbopol 940 was dispersed over this solution and kept to hydrate $12 \mathrm{~h}$. The solution was stirred with an overhead stirrer. DIC-loaded microsponges (equivalent to $0.1 \mathrm{gm}$ DIC) were dispersed in distilled water and added to the polymeric solution. Benzalkonium chloride was mixed to the prepared solution. Required amount of distilled water was added to make up the volume to $100 \mathrm{ml}$. Prepared in situ gel

\begin{tabular}{|c|c|c|c|c|}
\hline Ingredient $(\% \mathrm{~W} / \mathrm{V})$ & IG1 & IG2 & IG3 & IG4 \\
\hline Carbopol 940 & 0.1 & 0.1 & 0.1 & 0.1 \\
\hline HPMC E4M & 0.2 & 0.4 & 0.6 & 0.8 \\
\hline Benzalkonium chloride & 0.02 & 0.02 & 0.02 & 0.02 \\
\hline Distilled water qs & 100 & 100 & 100 & 100 \\
\hline
\end{tabular}
formulation thoroughly agitated and sterilized in an autoclave at $121^{\circ} \mathrm{C}$ for $20 \mathrm{~min}[24,25]$.

Table 1: Composition of DIC loaded microsponge containing ocular in situ gel formulations 
Characterization of DIC loaded microsponges containing ocular in situ gel

\section{Determination of visual appearance and clarity}

The appearance and clarity ocular in situ gel formulations were evaluated by observing gel in front of black and white background in fluorescent light inside a bright, lightened cabinet.

\section{Determination of $\mathrm{pH}$}

The $\mathrm{pH}$ of in situ gel formulation was determined using a pH meter (Labindia, Mumbai, Model: GMPH) which was calibrated before use with the buffered solution at $\mathrm{pH} 4$ and 7 . Three readings were taken for every sample and the average of three samples was calculated.

\section{Drug content determination}

In situ gel formulation was added to $100 \mathrm{ml}$ volumetric flask. To this add $60 \mathrm{ml}$ of $\mathrm{pH} 7.4$ phosphate buffer was added and shaken for $4 \mathrm{~h}$. and filtered. Filtered solution was further diluted to $100 \mathrm{ml}$ with 7.4 phosphate buffer. Analyzed using UV spectrophotometer (UV1Jasco, Japan, Model: V-530) with phosphate buffer (pH 7.4) as blank. The drug content of the microsponges was calculated.

\section{Determination of gelling capacity}

To vial containing $2 \mathrm{ml}$ of freshly prepared STF (maintained at 37 ${ }^{\circ} \mathrm{C}$ ), drop of the in situ gel was added. The drop of in situ gel was observed and the time taken by drop for gelation was noted also the time taken for the gel formed to dissolve was noted [12]. Gelling capacity of formed in situ gel was noted as follows.

\section{$\theta \quad$ No gel formation}

$(+)$ The gel formation occur after few minutes and dissolves quickly

$(++)$ Instantaneous gel formation and resides for few hours

$(+++)$ Instantaneous stiff gel formation which resides for long period of time

\section{Rheological studies}

Brookfield digital viscometer (DVII+PRO) was used to measure the viscosity (in cps) of the prepared in situ gel formulations. The spindle (T-D) was rotated at $20 \mathrm{rpm}$. Three readings were reported $30 \mathrm{sec}$ after putting the motor on and an average calculated.

\section{In vitro drug release from In situ ocular gel containing DIC loaded microsponges}

The in vitro drug release from the in situ ocular gel was carried out as per procedure described above under 'In vitro drug release from DIC loaded microsponges'. The in situ ocular gel was placed on donor compartment. To the top of the in situ gel $250 \mu \mathrm{l}$ of the STF was added to simulate the small amount of tear secreted on the eye surface and covered with a coverslip. $1 \mathrm{ml}$ of samples were taken out at time intervals $0.25,0.5,1,2,3,4,5,6,7$ and $8 \mathrm{~h}$ with timely maintenance of sink condition. Samples were analyzed by using UV spectrophotometer [22]. In vitro drug release studies performed thrice for each in situ gel formulation.

In vitro drug release kinetic study of in situ ocular gel containing DIC loaded microsponges

Kinetic study of drug release data was performed ocular in situ gel as described above under 'In vitro drug release kinetic study of DIC loaded microsponges'.

\section{Sterility study}

The sterility study was performed according to Indian Pharmacopoeia [26]. In situ ocular gel formulation was directly inoculated aseptically into fluid thioglycolate medium $(20 \mathrm{ml})$, and incubated for $14 \mathrm{~d}$ at $30{ }^{\circ} \mathrm{C}$ to $35^{\circ} \mathrm{C}$. Separately, In situ ocular gel formulation was directly inoculated aseptically into soyabean-casein digest medium $(20 \mathrm{ml})$ and incubated for $14 \mathrm{~d} 20^{\circ} \mathrm{C}$ to $25^{\circ} \mathrm{C}$. Microbial contamination was tested with a Fluid thioglycollate medium and the presence of fungi tested with soybean-casein digest medium with incubation under aerobic conditions. The tests were performed in triplicate under aseptic conditions to avoid accidental contamination. The positive and negative controls were performed for the examination of growth promotion and sterility, respectively.

\section{RESULTS}

Characterization DIC loaded microsponge formulations

Production yield (\%), drug content (\%) and entrapment efficiency (\%)

With increase in polymer: drug ratio there is increment in production yield, drug content and entrapment efficiency. Production yield varied between $27.50 \%$ and $72.50 \%$. At low DIC concentration production yield was found extremely low $(27.50 \%)$. Drug content varied from $27.27 \%$ to $90.15 \%$ (table 2).

\section{Particle size analysis}

Particle size is an important parameter in ocular administration of particular system. Particle size range from $20.39 \pm 4.21 \mu \mathrm{m}$ and $0.78 \pm 0.11 \mu \mathrm{m}$. Particle size decreased as an increase in Polymer: drug ratio. This finding is in accordance with literature [2].

\section{In vitro drug release of DIC loaded microsponges}

In vitro drug release is graphically presented in fig. 1 . Formulation DERS4 $(87.94 \%)$ and DERS5 $(90.73 \%)$ showed relatively comparable drug release as compared to DERS3 (79.41\%) at the end of 6 h. Study revealed that the highest cumulative drug release after $6 \mathrm{~h}$ is $90.73 \%$.

\section{Kinetic analysis of the in vitro release data of DIC loaded microsponge formulations}

The release of DIC in both DIC-loaded microsponges formulations DERS3 and DERS4 showed more adherence to Higuchi's diffusion kinetic model, with regression coefficient $\left(\mathrm{r}^{2}\right)$ value 0.9730 and 0.9655 , respectively (table 3 ).

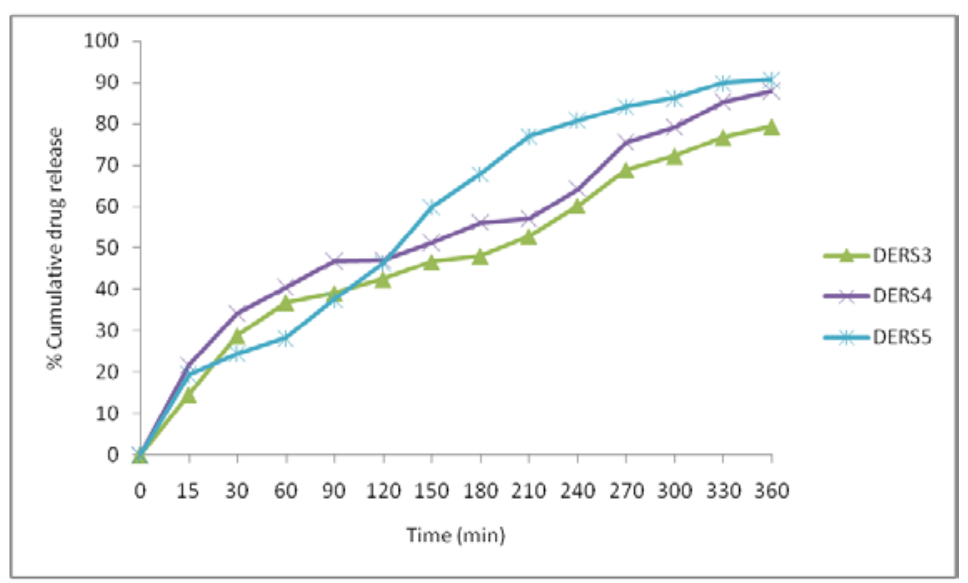

Fig. 1: In vitro release profiles of DIC loaded microsponge formulations (DERS3, DERS4 and DERS5). The data is expressed as mean \pm SD, $n=3$ 
Table 2: Characterization data of DIC loaded microsponges

\begin{tabular}{|c|c|c|c|c|c|c|}
\hline S. No. & $\begin{array}{l}\text { Formulation } \\
\text { code }\end{array}$ & $\begin{array}{l}\text { Polymer: drug } \\
\text { ratio }\end{array}$ & Particle size $(\mu \mathrm{m})$ & Production yield (\%) & Drug content (\%) & Entrapment efficiency (\%) \\
\hline 1 & DERS1 & $1: 1$ & $20.39 \pm 4.21$ & $27.50 \pm 3.54$ & $27.27 \pm 5.43$ & $15.00 \pm 3.15$ \\
\hline 2 & DERS2 & $1: 3$ & $13.14 \pm 2.63$ & $43.75 \pm 2.51$ & $45.71 \pm 4.92$ & $26.67 \pm 4.84$ \\
\hline 3 & DERS3 & $1: 5$ & $8.32 \pm 1.94$ & $57.50 \pm 4.13$ & $73.91 \pm 3.46$ & $51.00 \pm 3.61$ \\
\hline 4 & DERS4 & $1: 7$ & $7.52 \pm 2.29$ & $68.13 \pm 3.98$ & $80.73 \pm 3.51$ & $62.86 \pm 5.49$ \\
\hline 5 & DERS5 & 1: 9 & $6.98 \pm 1.45$ & $64.00 \pm 4.56$ & $86.72 \pm 1.36$ & $61.67 \pm 2.27$ \\
\hline 6 & DERS6 & $1: 11$ & $1.64 \pm 0.82$ & $68.75 \pm 1.32$ & $87.88 \pm 2.40$ & $65.91 \pm 3.65$ \\
\hline 7 & DERS7 & $1: 13$ & $0.78 \pm 0.11$ & $72.50 \pm 2.12$ & $90.15 \pm 4.22$ & $70.38 \pm 1.74$ \\
\hline
\end{tabular}

$*_{\mathrm{n}}=3$, mean $\pm \mathrm{SD}$

Table 3: Release kinetics study of DIC loaded microsponge formulations

\begin{tabular}{lllll}
\hline $\begin{array}{l}\text { Formulation } \\
\text { code }\end{array}$ & $\begin{array}{l}\text { Zero-order model } \\
\left(\mathbf{r}^{2}\right)\end{array}$ & $\begin{array}{l}\text { First-order model } \\
\left(\mathbf{r}^{2}\right)\end{array}$ & $\begin{array}{l}\text { Higuchi model } \\
\left(\mathbf{r}^{2}\right)\end{array}$ & $\begin{array}{l}\text { Hixson-crowell model } \\
\left(\mathbf{r}^{2}\right)\end{array}$ \\
\hline DSER3 & 0.9271 & 0.9602 & 0.9730 & 0.9625 \\
DSER4 & 0.9139 & 0.9301 & 0.9655 & 0.9483 \\
DSER5 & 0.9373 & 0.9883 & 0.9772 & 0.9861 \\
\hline
\end{tabular}

DERS5 followed first-order drug release kinetic, with regression coefficient $\left(\mathrm{r}^{2}\right)$ value 0.9883 . The diffusion exponents ( $\mathrm{n}$ ) of all microsponge formulations have a value more than 0.5 but less than 0.8. This indicates that the DIC release mechanism from microsponges is non-Fickian diffusion.

Microsponge formulation DERS4 was selected as having requisite particle size, sustained release and satisfactory Production yield, Entrapment efficiency and Drug content. DERS4 was further studied for FTIR, DSC and SEM.

\section{Fourier transform infrared spectroscopy (FTIR)}

Drug-polymer compatibility in the selected microsponges DERS4 was evaluated by FTIR. The principle IR peaks of DIC appeared at wavenumbers of $3361.34 \mathrm{~cm}^{-1}$ (NH starching of secondary amine groups), $1302.12 \mathrm{~cm}^{-1}$ (C-N stretching), $1503.46 \mathrm{~cm}^{-1}$ (C=C ring stretching) and $1548.76 \mathrm{~cm}^{-1}$ ( $\mathrm{C}=0$ stretching of the carboxyl ion) and $757.12 \mathrm{~cm}^{-1}$ (C-Cl stretching) [27]. The characteristic DIC peaks were present in the physical mixture as well as in the DIC-loaded microsponges DERS4 (fig. 2) with no significant changes in frequencies.

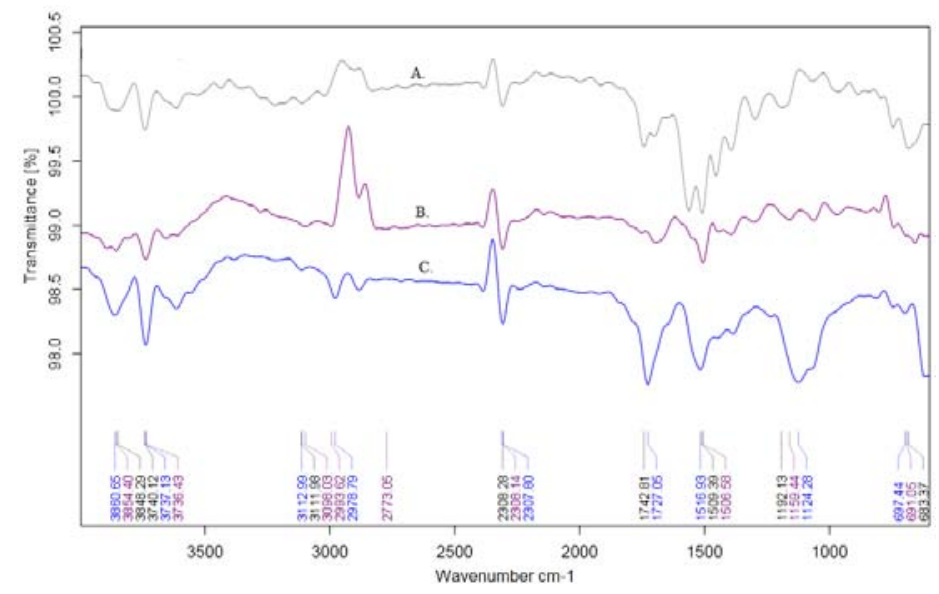

Fig. 2: FTIR spectrum of (a) DIC (b) Physical mixture of DIC and ERS polymer (c) Selected microsponge formulation DERS4

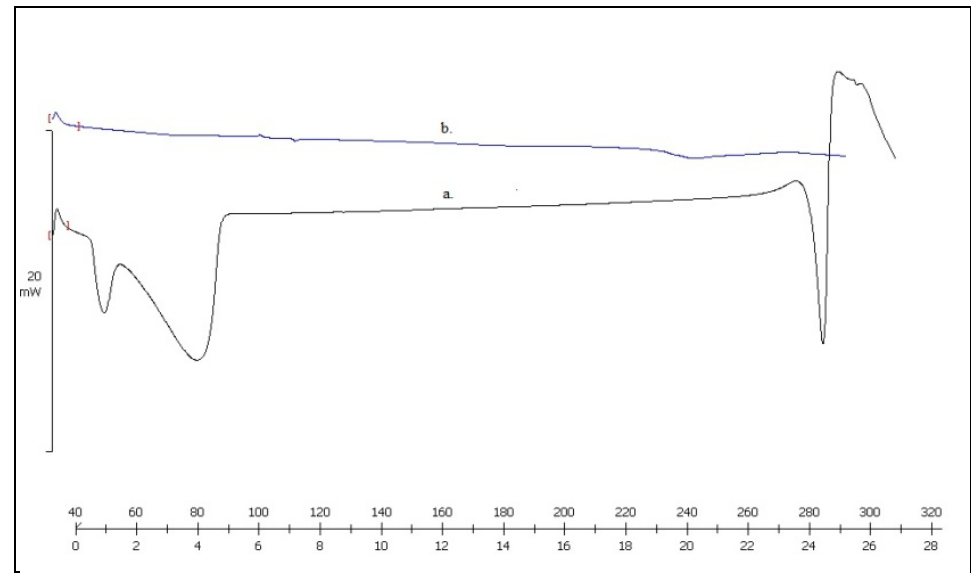

Fig. 3 DSC thermogram of (a) Pure DIC and (b) Selected microsponge DERS4 


\section{Differential scanning calorimetry (DSC)}

The thermal behavior of the DIC, and selected microsponge DERS4 are presented in (fig. 3).

DSC thermogram of DIC exhibited endothermic peaks, initial peak due to loss of water followed by the other sharp endothermic peak at $291.97{ }^{\circ} \mathrm{C}$, indicating to melting point of DIC in crystalline form; reflecting DIC purity [9]. The DSC curves of DERS4 formulation exhibited suppressed peak of the DIC at $280.40{ }^{\circ} \mathrm{C}$

\section{Scanning electron microscopy (SEM)}

Morphology DIC loaded microsponges were studied by SEM analysis. The representative SEM images of microsponge (DERS4) are shown in (fig. 4 and 5)

Formulation and characterization of in situ ocular gel containing DIC loaded Microsponges

In situ ocular gel found clear with suspended microsponge particles. The $\mathrm{pH}$ of in situ gel solution was found in range 6.03 to 6.13.

The formulation have an optimum viscosity at Non-Physiological conditions that will give ease in instillation to eye in the form of drop, which go through a quick sol to gel transition (triggered by $\mathrm{pH}$ ) at physiological conditions $\left(37^{\circ} \mathrm{C}\right.$ and $\left.7.4 \mathrm{pH}\right)$ as shown in table 4 .

The in vitro drug release from in situ ocular gel showed sustained release. The \% cumulative drug release from formulations was found to be IG1 (89.25\%), IG2 (84.23\%), IG3 (76.92\%), and IG4 $(69.64 \%)$ after $8 \mathrm{~h}$ as shown in fig. 6 .

The drug release kinetic of all in situ gel formulations suggests Higuchi kinetic model (table 5) and diffusion exponent showed nonfickian diffusion mechanism.

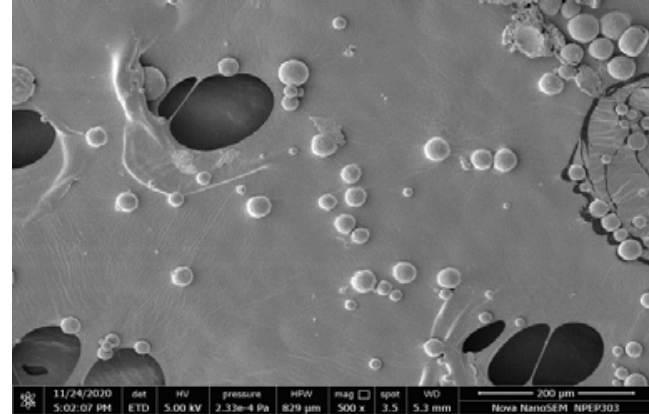

Fig. 4: SEM of selected microsponge DERS4 (Magnification $x$ 500)

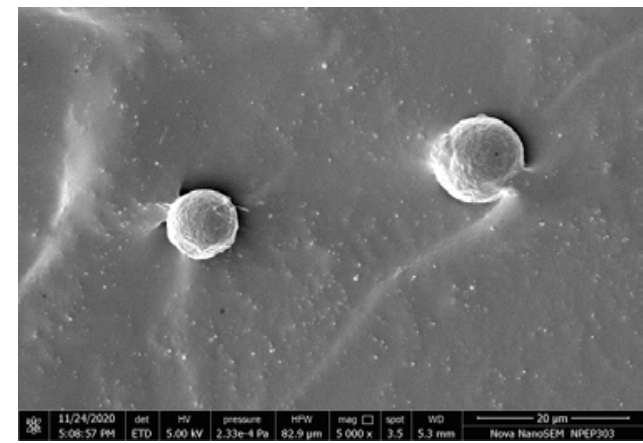

Fig. 5: SEM of selected microsponge DERS4 (Magnification $x$ 5000)

Table 4: Characterization of DIC loaded microsponge containing ocular in situ gel

\begin{tabular}{|c|c|c|c|c|c|}
\hline Formulat & on code & IG1 & IG2 & IG3 & IG4 \\
\hline Gelling ca & acity & + & ++ & ++ & +++ \\
\hline $\mathrm{pH}$ & & 6.04 & 6.03 & 6.13 & 6.10 \\
\hline Viscosity & At Non-Physiological conditions & $860 \pm 120$ & $1008 \pm 142$ & $1843 \pm 176$ & $2308 \pm 241$ \\
\hline$(\mathrm{cP})$ & At Physiological conditions ( $\mathrm{pH} 7.4$ and $\left.37^{\circ} \mathrm{C}\right)$ & $1852 \pm 194$ & $4340 \pm 241$ & $6651 \pm 186$ & $7035 \pm 108$ \\
\hline \multicolumn{2}{|c|}{ Drug content $(\%)$} & $86.54 \pm 1.74$ & $90.73 \pm 1.40$ & $94.26 \pm 1.61$ & $89.83 \pm 2.24$ \\
\hline
\end{tabular}

$* \mathrm{n}=3$, mean $\pm \mathrm{SD}$

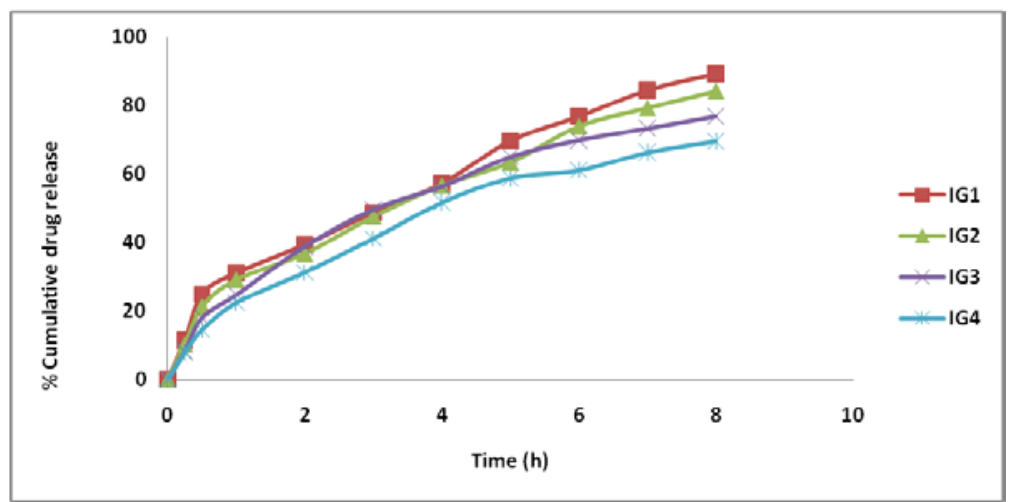

Fig. 6: In vitro release profiles of DIC loaded microsponge containing ocular in situ gel. The data is expressed as mean \pm SD, $n=3$

Table 5: Release kinetics study of DIC loaded microsponge containing ocular in situ gel

\begin{tabular}{lllll}
\hline $\begin{array}{l}\text { Formulation } \\
\text { code }\end{array}$ & $\begin{array}{l}\text { Zero order model } \\
\left(\mathbf{r}^{2}\right)\end{array}$ & $\begin{array}{l}\text { First order model } \\
\left(\mathbf{r}^{\mathbf{2}}\right)\end{array}$ & $\begin{array}{l}\text { Higuchi model } \\
\left(\mathbf{r}^{2}\right)\end{array}$ & $\begin{array}{l}\text { Hixson-crowell model } \\
\left(\mathbf{r}^{2}\right)\end{array}$ \\
\hline IG1 & 0.9536 & 0.9755 & 0.9900 & 0.9880 \\
IG) & 0.9884 & 0.9936 & 0.9904 \\
IG3 & 0.9536 & 0.9904 & 0.9941 & 0.9753 \\
IG4 & 0.9260 & 0.9877 & 0.9931 & 0.9763 \\
\hline
\end{tabular}




\section{Sterility study}

The study results of the sterility study are summarized in table 6, the prepared ocular in situ gel formulation passed the sterility test. There was zero growth found in fluid thioglycollate medium and soyabean casein digest medium.

Table 6: Sterility test of ocular in situ gel formulation IG3

\begin{tabular}{lll}
\hline Organism & Bacteria & Fungi \\
\hline +ve Control & Turbid & Turbid \\
-ve Control & Clear & Clear \\
IG3 & Clear & Clear \\
\hline
\end{tabular}

${ }^{*} \mathrm{n}=3$, mean $\pm \mathrm{SD}$

\section{DISCUSSION}

DIC-loaded microsponges were prepared by the quasi emulsion solvent diffusion method using ERS polymer. In literature, this method is considered to be simple, replicable, rapid and solvent toxicity also got eliminated [3]. With the increase in drug concentration in polymer: drug ratio; production yield, drug content and entrapment efficiency increases. As more drug are available for entrapment leading to high amount of drugs in microsponges leading to increased values of production yield, drug content and entrapment efficiency. The lower values of entrapment efficiency $(15.00 \%)$ could be due to dissolution of some fraction of DIC in PVA solution during the emulsification process [20]. With an increase in level of DIC (besides drug dissolution), more drugs available for entrapment in ERS polymer matrix. As a result entrapment efficiency increases with increment in polymer: drug ratio.

High PVA concentration and high stirring speed yield small particle size which is requisite for this study. In the quasi emulsion solvent diffusion method, organic phase i.e. dichloromethane diffuses out to yield particles in which drug particle surrounded by polymer. At high polymer: drug ratio less polymer amounts surrounds the drug causing decreased particle sizes of microsponges [2].

As in the polymer: drug ratio the concentration of drug increased, polymer units surrounding drug units is less than at low. During phase transition process less polymer got bound to the drug giving smaller size microsponge. Particle size of less than $10 \mu \mathrm{m}$ is required for ocular administration [11]. Hence microsponge formulations above $10 \mu \mathrm{m}$ were not further investigated. Microsponges have particle size range from 5-300 $\mu \mathrm{m}$. So microsponges below $5 \mu \mathrm{m}$ were also excluded from further studies.

Sustained release of drug was as a result of incorporation of drug in polymer Matrix [28]. Drug release is inversely related to the Polymer: drug ratio. High Polymer: drug ratio yield smaller particles having more active surface area which coming in contact with diffusion media. Also smaller particle exhibit shorter path length drug need to travel through microsponge pores into the diffusion media [8]. Drug release rates were increased with an increasing amount of DIC in microsponge. At a high Polymer: drug ratio, the corresponding polymer amount is lesser. As more drug got released more void channels formed which allows more diffusion media to enter and in turn increases release rate.

FTIR studies confirms that no interaction between drug and ERS polymer. The thermogram of microsponge formulation showed suppressed peak signify uniform dispersion of DIC in polymeric matrix and altered crystallinity of DIC. Absence of any other significant endothermic peak, in the melting point range of DIC (melting point found as $286.26^{\circ} \mathrm{C}$ ) indicates that absence of any interaction between the DIC and ERS polymer, and verify the aptness of microsponge preparation technique [27].

SEM results indicated that DERS4 microsponges were tiny, porous and spherical. Surface integrity of microsponge got retained. Microsponges particles are free from aggregates. This might be due to aqueous solution of PVA which is used during the quasi emulsion solvent diffusion method. PVA reduces surface charge on the particle giving aggregate free microsponges [29].
In the present investigation, incorporation of DIC-loaded ERS polymeric microsponges was performed into in situ gel formulated using polymers Carbopol 940 and HPMC E4M. Carbopol 940 and HPMC E4M were used in combination as alone high concentration of carbopol 940 yield a highly acidic solution, which is not suitable for ocular administration ( $\mathrm{pH}$ of lacrimal fluid 7.4) [30]. So moderate concentration of Carbopol $940(0.1 \% \mathrm{w} / \mathrm{v})$ along with viscosityenhancing polymer HPMC E4M (0.2-0.8\% w/v) [31] was used to formulate in situ gel. The $\mathrm{pH}$ of formulation would raises instantly to $\mathrm{pH} 7.4$ (an ideal ocular $\mathrm{pH}$ ) after instillation into eye due to $\mathrm{pH}$ of lacrimal secretion. Thus, the formulations were considered to be suitable for ocular administration and may not cause any irritation to ocular tissues upon instillation [25].

At Physiological conditions formulation form stiff gel which increases residence time of microsponges incorporated in gel. In situ gel formulation contains HPMC E4M and carbopol 940 which are known to gel reversibly on elevation of temperature and $\mathrm{pH}$ respectively [31]. Hence at physiological conditions viscosity of formulation increases to form a stiff gel, as both $\mathrm{pH}$ and temperature increases.

Formed stiff gel should display good integrity and not to get dissolve and erode for extended period of time. Formulations IG2 and IG3 exhibited satisfactory “++" grade of gelling capacity [12].

In situ gel formulation IG3 showed sustained release with a satisfactory "++" grade of gelling capacity. Hence, IG3 formulation was taken for further Sterility test. Sterility study results proved the efficiency of autoclaving for sterilization of ocular in situ gel.

\section{CONCLUSION}

With the present study, the potential of DIC loaded microsponges as drug carriers for ocular delivery was investigated. Microsponges showed good practical yield, entrapment efficiency, drug content and suitable particle size for ocular administration. Controlled release of up to $6 \mathrm{~h}$ observed through DIC loaded microsponges. DIC loaded microsponges successfully incorporated in in situ gels. The clarity, pH, drug content, gelling capacity and rheological studies of DIC loaded microsponges containing ocular in situ gel formulations were found to be acceptable. Further, in situ gel formulations showed sustained drug release for a period of $8 \mathrm{~h}$, which is satisfactory for management of ocular pain.

\section{ACKNOWLEDGEMENT}

The authors express sincere thanks to Dr. R. S. Chavan, Principal, PDEA's S. G. R. S. College of Pharmacy, Saswad, Purandar, Pune, Maharashtra, India for providing the facilities needed to undertake this research work.

\section{ETHICS APPROVAL AND CONSENT TO PARTICIPATE}

\section{Not applicable}

\section{ABBREVIATIONS}

DIC: Diclofenac Sodium; ERS: Eudragit RS 100; HPMC E4M: Hydroxypropyl Methylcellulose E4M; DMC: Dichloromethane; PVA: Polyvinylalcohol; FTIR: Fourier Transform Infrared Spectroscopy; DSC: Differential scanning calorimetry; SEM: Scanning electron microscopy; STF: Simulated tear fluid.

\section{FUNDING}

This research did not receive any specific grant from funding agencies in public, commercial or not-for-profit sectors.

\section{AUTHORS CONTRIBUTIONS}

All authors have read and approved the manuscript. Rajashri B. Ambikardesigned the study, carried out experimental work, Analyzed data and Drafted the manuscript. Dr. Ashok V. Bhosale contributed in designing of study, checked the paper content, helped in data interpretation and critical revision of the manuscript for intellectual content.

\section{CONFLICT OF INTERESTS}

The authors declare no competing interests. 


\section{REFERENCES}

1. Osmani RA, Aloorkar NH, Kulkarni AS, Thaware BU, Kulkarni PK. Microsponge based drug delivery system for augmented gastroparesis therapy: formulation development and evaluation. Asian J Pharm Sci 2015;10:442-51.

2. Nokhodchi A, Jelvehgari M, Siahi MR, Mozafari MR. Factors affecting the morphology of benzoyl peroxide microsponges. Micron 2007;38:834-40.

3. Kumari A, Jain A, Hurkat P, Tiwari A, Jain SK. Eudragit S100 coated microsponges for Colon targeting of prednisolone. Drug Dev Ind Pharm 2018;44:902-13.

4. Sareen R, Nath K, Jain N, Dhar KL. Curcumin loaded microsponges for colon targeting in inflammatory bowel disease: fabrication, optimization, and in vitro and pharmacodynamic evaluation. J Biomed Biotechnol 2014. DOI:10.1155/2014/340701.

5. Srivastava R, Kumar D, Pathak K. Colonic luminal surface retentive Meloxi-cam microsponges delivered by erosion based colon targeted matrix tablet. Int J Pharm 2012;427:156-62.

6. Bhatia M, Saini M. Formulation and evaluation of curcumin microsponges for oral and topical drug delivery. Prog Biomater 2018;7:239-48.

7. Abdelmalak NS, El-Menshawe SF. A new topical fluconazole microsponge loaded hydrogel: preparation and characterization. Int J Pharm Pharm Sci 2012;4:460-9.

8. Arya P, Pathak K. Assessing the viability of microsponges as gastro retentive drug delivery system of curcumin: Optimization and pharmacokinetics. Int J Pharm 2014;460:1-12.

9. Maiti S, Kaity S, Ray S, Sa B. Development and evaluation of xanthan gum-facilitated ethyl cellulose microsponges for controlled percutaneous delivery of diclofenac sodium. Acta Pharm 2011;61:257-70.

10. Ambikar RB, Bhosale AV. Formulation and evaluation of eudragit Rl100 polymeric drug loaded microsponge for ophthalmic use. J Pharm Res Int 2021;33:45-51.

11. Abd-Elal RMA, Elosaily GH, Gad S. Full factorial design, optimization, in vitro and ex vivo studies of ocular timololloaded microsponges. J Pharm Innov 2020;15:651-63.

12. Obiedallah MM, Abdel-Mageed AM, Elfaham TH. Ocular administration of acetazolamide microsponges in situ gel formulations. Saudi Pharm J 2018;26:909-20.

13. Ali J, Fazil M, Qumbar M, Khan N, Ali A. Colloidal drug delivery system: amplify the ocular delivery. Drug Delivery 2016;23:710-26.

14. Kesarla R, Tank T, Vora PA, Shah T, Parmar S, Omri A. Preparation and evaluation of nanoparticles loaded ophthalmic in situ gel. Drug Delivery 2016;23:2363-70.

15. Upadhayay $P$, Kumar M, Pathak K. Norfloxacin loaded $\mathrm{pH}$ triggered nanoparticulate in-situ gel for extraocular bacterial infections: optimization, ocular irritancy and corneal toxicity. Iran J Pharm Sci 2016;15:3-22.

16. Al-Kinani A, Zidan G, Elsaid N, Seyfoddin A, Alani AW, Alany R. Ophthalmic gels: past, present and future. Adv Drug Delivery Rev 2018;126:113-26.

17. Wu Y, Liu Y, Li X, Kebebe D, Zhang B, Ren J, et al. Research progress of in-situ gelling ophthalmic drug delivery system. Asian J Pharm Sci 2019;14:1-15.
18. Khangtragool A. Methocel E4M: preparation and properties as a vehicle for the ocular drug delivery of vancomycin, Chiang Mai J Sci 2014;41:166-73.

19. Adelli GR, Balguri SP, Bhagav P, Raman V, Majumdar S. Diclofenac sodium ion exchange resin complex loaded melt cast films for sustained release ocular delivery. Drug Delivery 2017;24:370-9.

20. Jelvehgari M, Siahi Shadbad MR, Azarmi S, Martin GP, Nokhodchi A. The microsponge delivery system of benzoyl peroxide: preparation, characterization and release studies. Int J Pharm 2006;308:124-32.

21. Martin A, Bustamante P, Chun A. Micromeritics. In: Physical pharmacy-physical chemical principles in the pharmaceutical science. $5^{\text {th }}$ ed. B I Waverly Pvt. Ltd; 2002. p. 446-8.

22. Nair AB, Shah J, Jacob S, Al-Dhubiab BE, Sreeharsha N Experimental design, formulation and in vivo evaluation of a novel topical in situ gel system to treat ocular infections. PLoS One 2021;16:e0248857.

23. Son GH, Lee BJ, Cho CW. Mechanisms of drug release from advanced drug formulations such as polymeric-based drugdelivery systems and lipid nanoparticles. Int J Pharm Investig 2017;47:287-96.

24. Li SS, Li GF, Liu L, Jiang X, Zhang B, Liu ZG, et al. Evaluation of paeonol skin-target delivery from its microsponge formulation: in vitro skin permeation and in vivo microdialysis. PLoS One 2013;20;8:e79881.

25. Song J, Bi H, Xie X, Guo J, Wang X, Liu D. Preparation and evaluation of sinomenine hydrochloride in situ gel for uveitis treatment Int. Immunopharmacol 2013;17:99-107.

26. Indian Pharmacopoeia. The controller of publication, New Delhi; Ministry of health and family welfare. India. $6^{\text {th }}$ Eed. Volume II; 2010. p. 59-66.

27. Kucukturkmen B, Oz UC, Bozkir A. In situ hydrogel formulation for intra-articular application of diclofenac sodium-loaded polymeric nanoparticles. Turk J Pharm Sci 2017;14:56-64.

28. Kumar PM, Ghosh A. Development and evaluation of metronidazole loaded microsponge based gel for superficial surgical wound infections.J Drug Delivery Sci Technol 2015;30:15-29.

29. Deshmukh K, Poddar SS. Tyrosinase inhibitor-loaded microsponge drug delivery system: new approach for hyperpigmentation disorders. J Microencapsul 2012; 29:559-68.

30. Charoo NA, Kohli K, Ali A. Preparation of in situ-forming ophthalmic gels of ciprofloxacin hydrochloride for the treatment of bacterial conjunctivitis: in vitro and in vivo studies. J Pharm Sci 2003;92:407-13.

31. Makwana SB, Patel VA, Parmar SJ. Development and characterization of in-situ gel for ophthalmic formulation containing ciprofloxacin hydrochloride Results Pharma Sci 2016;6:1-6.

32. Sheshala R, Ming NJ, Kok YY, Singh TRR, Dua K. Formulation and characterization of $\mathrm{pH}$ induced in situ gels containing sulfacetamide sodium for ocular drug delivery: a combination of carbopol@/HPMC polymer. Indian J Pharm Educ Res 2019;53:654-62. 